\title{
Effect of glutamine supplementation on cardiometabolic risk factors and inflammatory markers: a systematic review and meta-analysis
}

Motahareh Hasani ${ }^{1}$, Asieh Mansour ${ }^{2,3}$, Hamid Asayesh $^{4 *}$, Shirin Djalalinia ${ }^{5,6}$, Armita Mahdavi Gorabi ${ }^{7}$, Fatemeh Ochi ${ }^{9}$ and Mostafa Qorbani $i^{8,10^{*}+}$

\begin{abstract}
Background: Evidence exists that glutamine plays multiple roles in glucose metabolism, insulin sensitivity, and anti-inflammatory effects. This systematic review and meta-analysis of controlled trials aimed to assess the effect of glutamine supplementation on cardio-metabolic risk factors and inflammatory markers.
\end{abstract}

Methods: The processes of systematic reviews and meta-analyses were performed according to the PRISMA checklist. PubMed, Web of Sciences, Cochrane library, and Scopus databases were search for relevant studies without time or language restrictions up to December 30,2020. All randomized clinical trials which assessed the effect of glutamine supplementation on "glycemic indices", "level of triglyceride, "and "inflammatory markers" were included in the study. The effect of glutamine supplementation on cardio-metabolic risk factors and inflammatory markers was assessed using a standardized mean difference (SMD) and 95\% confidence interval (Cl). Heterogeneity between among studies was assessed using Cochran Q-statistic and I-square. Random/fixed-effects meta-analysis method was used to estimate the pooled SMD. The risk of bias for the included trials was evaluated using the Cochrane quality assessment tool.

Results: In total, 12 studies that assessed the effect of glutamine supplementation on cardio-metabolic risk factors were included in the study. Meta-analysis showed that glutamine supplementation significantly decreased significantly serum levels of FPG [SMD: $\left.-0.73,95 \% \mathrm{Cl}-1.35,-0.11, \mathrm{I}^{2}: 84.1 \%\right]$ and CRP [SMD: $-0.58,95 \% \mathrm{Cl}-0.1,-0.17$, $\left.I^{2}: 0 \%\right]$. The effect of glutamine supplementation on other cardiometabolic risk factors was not statistically significant $(P>0.05)$.

Conclusion: Our findings showed that glutamine supplementation might have a positive effect on FPG and CRP; both of which are crucial as cardio-metabolic risk factors. However, supplementation had no significant effect on other cardio-metabolic risk factors.

\footnotetext{
*Correspondence: hasayesh@gmail.com; mqorbani1379@gmail.com ${ }^{\dagger}$ Hamid Asayesh and Mostafa Qorbani have contributed equally to this work

${ }^{4}$ Department of Medical Emergencies, Qom University of Medical Sciences, Qom, Iran

${ }^{8}$ Non-Communicable Diseases Research Center, Alborz University of Medical Sciences, Karaj, Iran

Full list of author information is available at the end of the article
}

(c) The Author(s) 2021. Open Access This article is licensed under a Creative Commons Attribution 4.0 International License, which permits use, sharing, adaptation, distribution and reproduction in any medium or format, as long as you give appropriate credit to the original author(s) and the source, provide a link to the Creative Commons licence, and indicate if changes were made. The images or other third party material in this article are included in the article's Creative Commons licence, unless indicated otherwise in a credit line to the material. If material is not included in the article's Creative Commons licence and your intended use is not permitted by statutory regulation or exceeds the permitted use, you will need to obtain permission directly from the copyright holder. To view a copy of this licence, visit http://creativecommons.org/licenses/by/4.0/. The Creative Commons Public Domain Dedication waiver (http://creativeco mmons.org/publicdomain/zero/1.0/) applies to the data made available in this article, unless otherwise stated in a credit line to the data. 
Keywords: Glutamine, Cardiometabolic risk factors, Systematic review, Meta-analysis

\section{Introduction}

Glutamine is the most abundant amino acid in the human body vital for one's health and plays an important role in boosting the immune system and carbohydrate metabolism [1]. In clinical practice, it has been shown that the glutamine supplementation can improve glucose homeostasis and reduce the need for exogenous insulin in patients with critical conditions [2]. Blood glucose levels in patients receiving glutamine supplementation were lower than those in controls, and this treatment might also reduce insulin requirements [3].

Previous studies have shown that glutamine can attenuate cytokine release from LPS-stimulated human peripheral blood mononuclear cells, and it can have various protective effects against cellular injury $[4,5]$. An in vitro study has demonstrated that glutamine can enhance glucose-stimulated insulin secretion, contributing to worsening insulin resistance of patients with multiple trauma [6]. The glutamine can reduce hyperglycemia by increasing insulin sensitivity and improving its signaling in peripheral tissues which directly stimulate insulin production by the pancreatic beta cells $[7,8]$. Moreover, glutamine supplementation enhances protein synthesis in catabolic/hypercatabolic conditions [9] and attenuates catabolic responses [10]. The findings of some studies support the hypothesis that glutamine supplementation as a dietary strategy can be beneficial in glycemic control in patients with type 2 diabetes and may be effective in controlling the obesity and diabetes $[11,12]$. On the other hand, the recent systematic review of the effect of glutamine supplementation on the glycemic profile of type 2 diabetic patients showed that glutamine improved insulin production; however, the results on other metabolic risk factors are controversial [13].

Some previous studies conducted human subjects showed the beneficial effects of glutamine enteral or parenteral supplementation on the intestinal integrity, immune-based responses, and the improvement in inflammatory markers and antioxidant capacity in intensive care unit patients as compared with a standard total parenteral nutrition (TPN) [14-17]. Arecent systematic review found that the effect of glutamine supplementation on inflammatory markers is inconclusive and controversial [13].

Given the multiple roles of glutamine in glucose metabolism, insulin sensitivity and its anti-inflammatory, and lack of meta-analysis examining the pooled effect of glutamine supplementation on cardiometabolic risk factors and inflammatory markers; therefore, the effects of glutamine supplementation on these factors remain to be elucidated. This systematic review and meta-analysis of randomized controlled trials (RCTs) aimed to pool the effect of glutamine supplementation on the cardiometabolic risk factors and inflammatory markers.

\section{Methods}

In this systematic review and meta-analysis, the probable effects of glutamine supplementation on cardiometabolic risk factors and inflammatory markers were assessed according to the "Preferred Reporting Items for Systematic Reviews Meta-Analyses" (PRISMA) checklist.

\section{Study selection}

All randomized controlled trials (RCTs), parallel or crossover design study, in adults or children population with any health condition, were included in this systematic review. The included studies should have assessed any form of glutamine supplementation (oral/TPN)) compared to placebo. Fasting plasma glucose (FPG), insulin, homeostasis model of assessment-estimated insulin resistance (HOMA-IR), quantitative insulin sensitivity check index (QUIKI), triglyceride (TG) were the primary outcomes. The secondary outcomes were inflammatory markers, such as C-reactive protein (CRP), Interleukin 6 (IL-6), Glutathione (GSH), Interleukin 1(IL-1), and Tumor necrosis factor alpha (TNF- $\alpha$ ).

\section{Search strategy}

To access all available related evidence, the most comprehensive international databases of PubMed/MEDLINE, Web of Science, Cochrane Library, and Scopus were searched for targeted papers without the time and language restrictions up to December 30, 2020. The search strategy was entering the terms of "glycemic indices", "level of triglyceride", "inflammatory markers," and "glutamine supplementation", without the restriction of ages of participants and time of publication. Reference lists of review papers are assessed to find related data. Grey literature and key journals were searched for additional data (Table 1).

\section{Inclusion and exclusion criteria}

We included studies used glutamine as a single therapy or combination therapy. Duplicate and non-relevant publications were excluded. To assess the relevancy of 
Table 1 Search strategy for selected databases

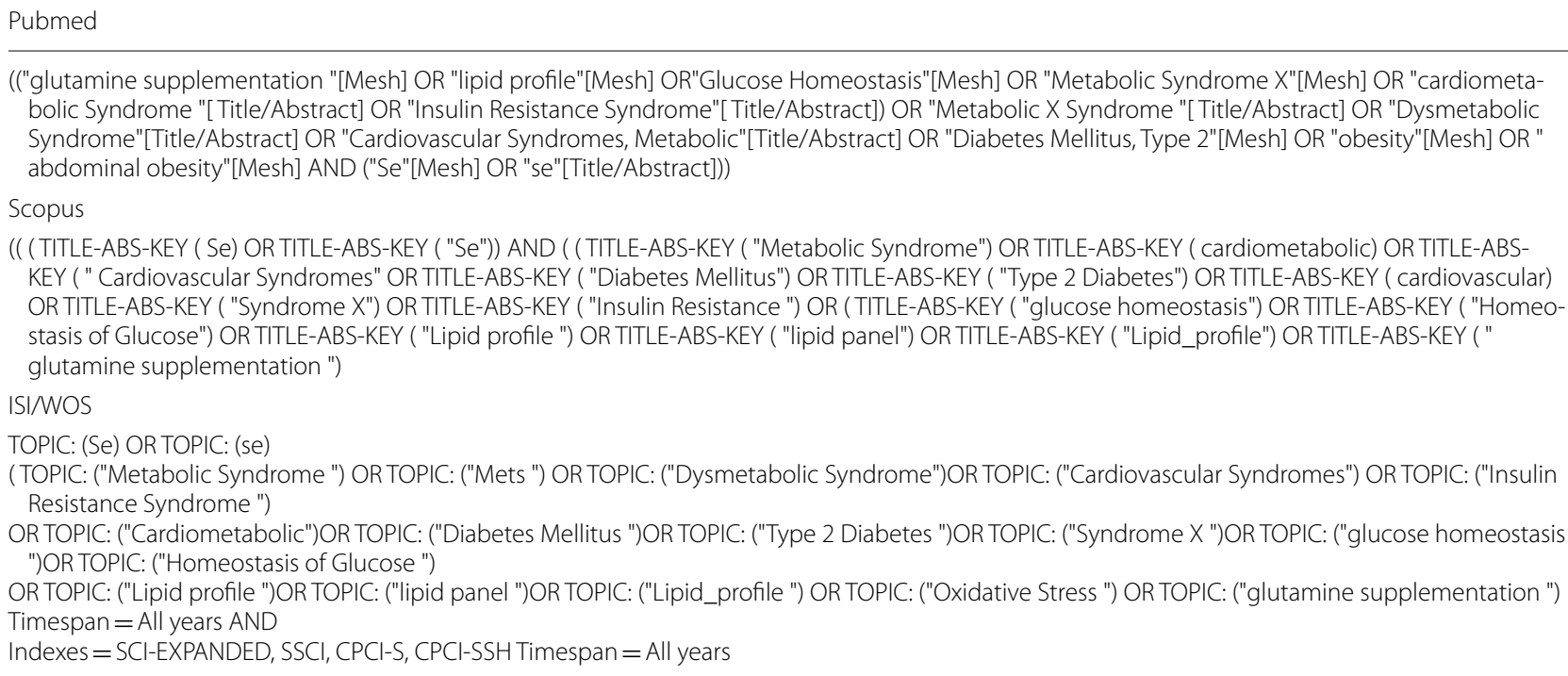

paper, three steps of refinements of titles, abstracts and the full texts were followed by two independent investigators. Possible disagreements were resolved by the third investigator.

\section{Data extraction}

Two independent investigators evaluated the eligibility criteria. The data related to citation information, details of study design, year of publication, the dose of supplementation, intervention group, control group, mean age of the participants, outcome, intervention duration, follow up information, measurements and result and effect size were extracted by using a data extraction sheet.

\section{Quality assessment}

The risk of bias for the included studies was evaluated using the Cochrane quality assessment tool for randomized trials [18]. Two independent investigators assessed the quality of studies using the following seven criteria: random sequence generation, allocation concealment, blinding of participants and personnel, blinding of outcome assessment, incomplete outcome data, selective reporting, and other bias sources. To evaluate the quality of studies, each study was allocated a label indicating that it was judged as low risk, high risk, or unknown risk of bias, respectively.

\section{Data synthesis and statistical analysis Glycemic indices}

The effect of glutamine supplementation on cardiometabolic risk factors and inflammatory markers was assessed using standardized mean difference (SMD) and 95\% confidence interval (CI). The data expressed as median and range were converted to mean and SD by applying the Hozo formula [18] and then SMD was calculated. A random-effect model was used if the Q-statistic for heterogeneity was significant at the level of 0.1 [18]. In other cases, the fixed-effect model was used [20]. The degree of heterogeneity was quantified using $\mathrm{I}^{2}$ statistics, which estimated the total variation across studies due to heterogeneity [21]. $\mathrm{I}^{2}$ values of $25 \%, 50 \%$, and $75 \%$ were considered to correspond to low, medium, and high heterogeneity levels, respectively. A randomeffect meta-regression analysis explored possible sources of heterogeneity (such as quality assessment score, the duration of intervention, study subjects, mean age of participants, dose of glutamine supplementation and female ration). Egger's test estimated publication bias, and results of Egger's test were considered as statistically significant at 0.1 . The statistical analysis was conducted using STATA version 11 [22]. $P$ value $\leq 0.05$ was considered as statistically significant.

\section{Ethical considerations}

The study protocol was approved by the ethical committee of NIMAD institute. All of the included studies would be cited in future relevant reports and publications.

\section{Results}

\section{Results of the search and the characteristics of included} studies

A flow chart showing the study selection process is shown in Fig. 1. A total of twelve studies were included in the final step of selection according to the inclusion/ 


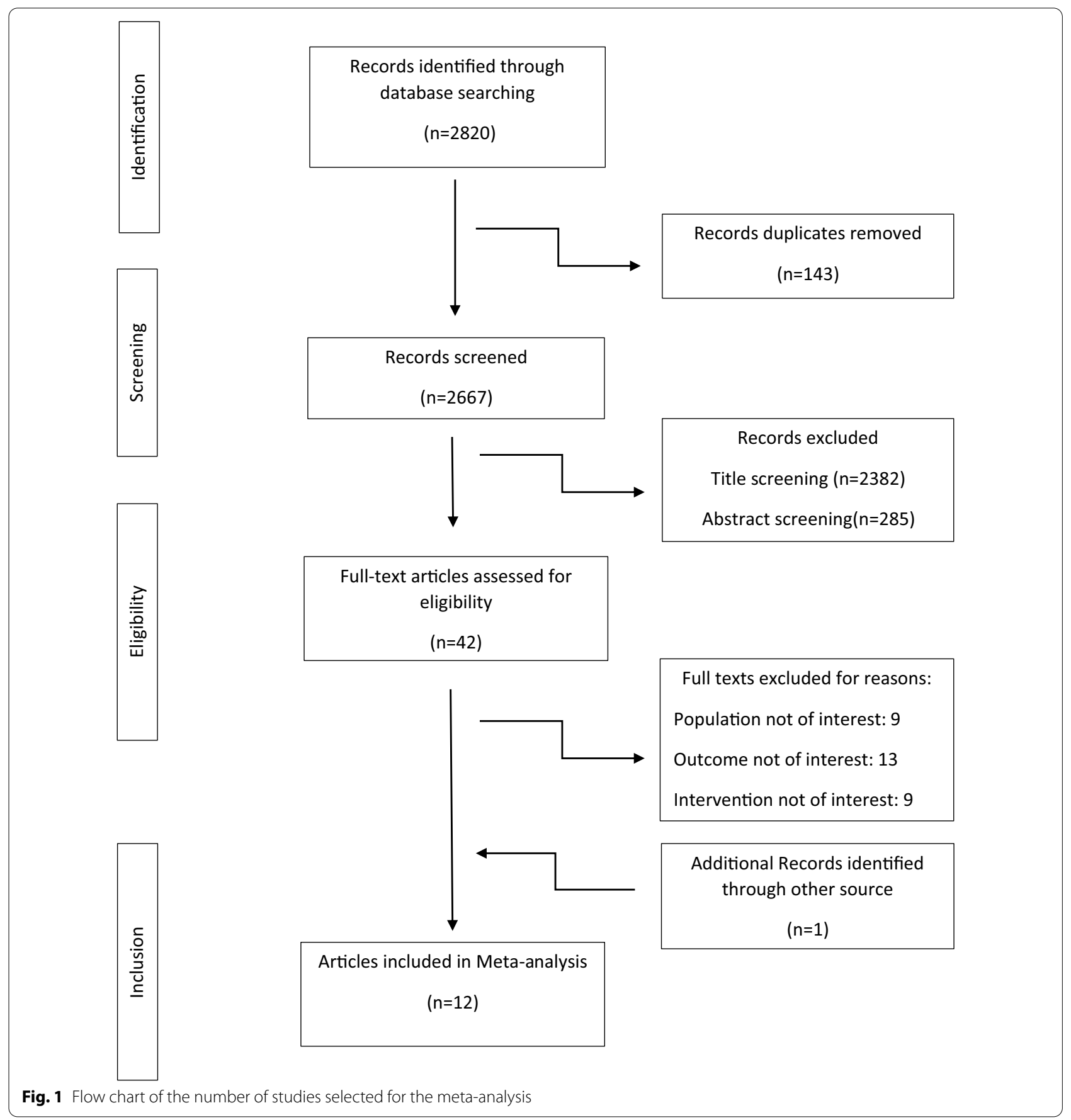

exclusion criteria. The characteristics of included studies are shown in Table 2.

The meta-analysis included 12 RCTs published between 2002 and 2015. In all studies, a total of 205 participants were randomly assigned to the intervention group and 173 participants to the control group. The age range of the participants was $10-71$ years. Eight RCT recruited both men and women [26-33].
Only female subjects were enrolled in one study [24] and only male participants were enrolled in the three studies [3, 23, 25]. Seven trials used glutamine as oral supplement $[3,23-25,29,30,33]$ and 5 trials used glutamine supplementation with parenteral way [26-28, $30,31]$. The dosage of glutamine supplements ranged from $0.3 \mathrm{mg} / \mathrm{kg} /$ day [33] to $50 \mathrm{gr} /$ day [29] and the intervention periods ranged from 0.5 days [23] to 120 days 


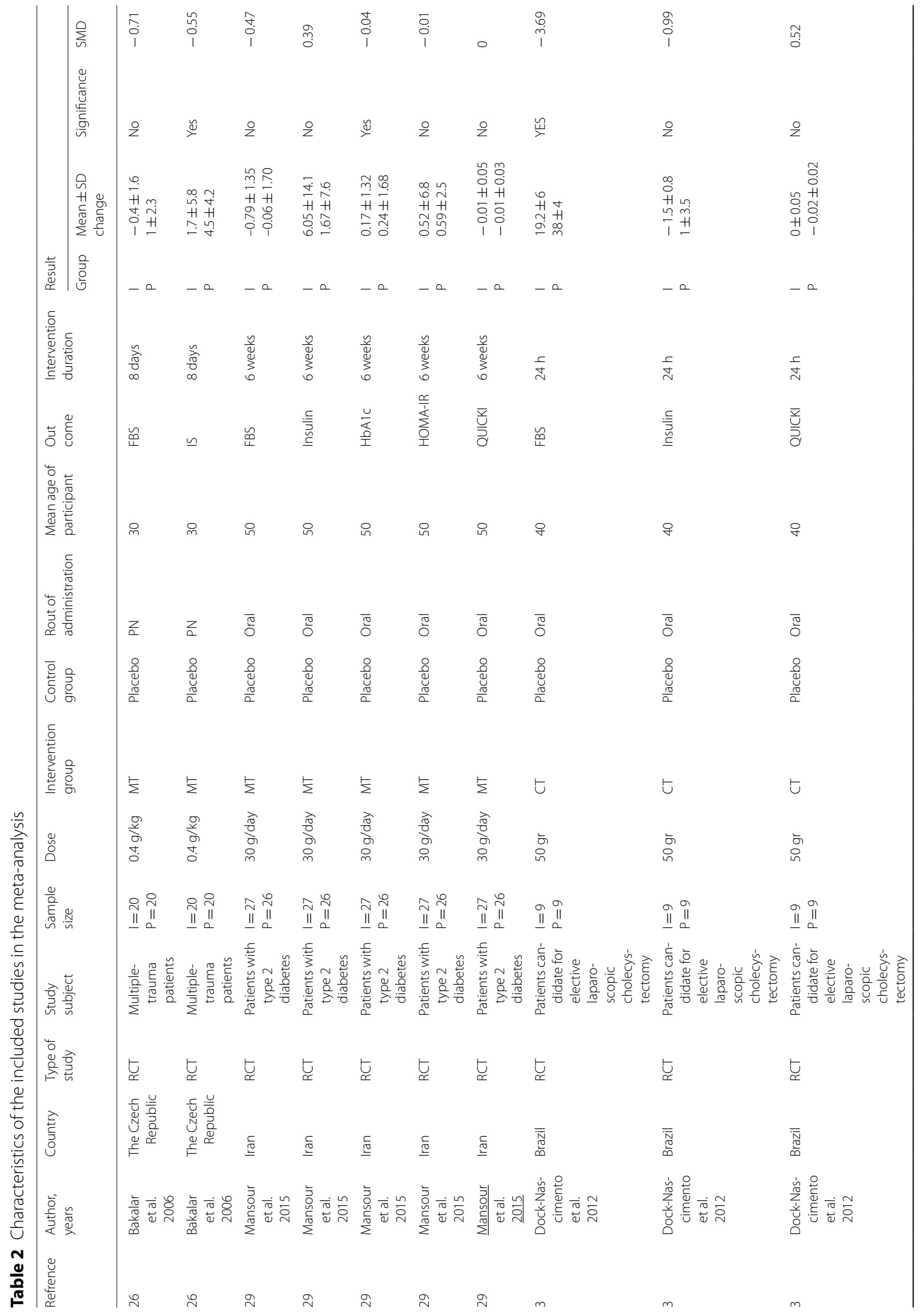




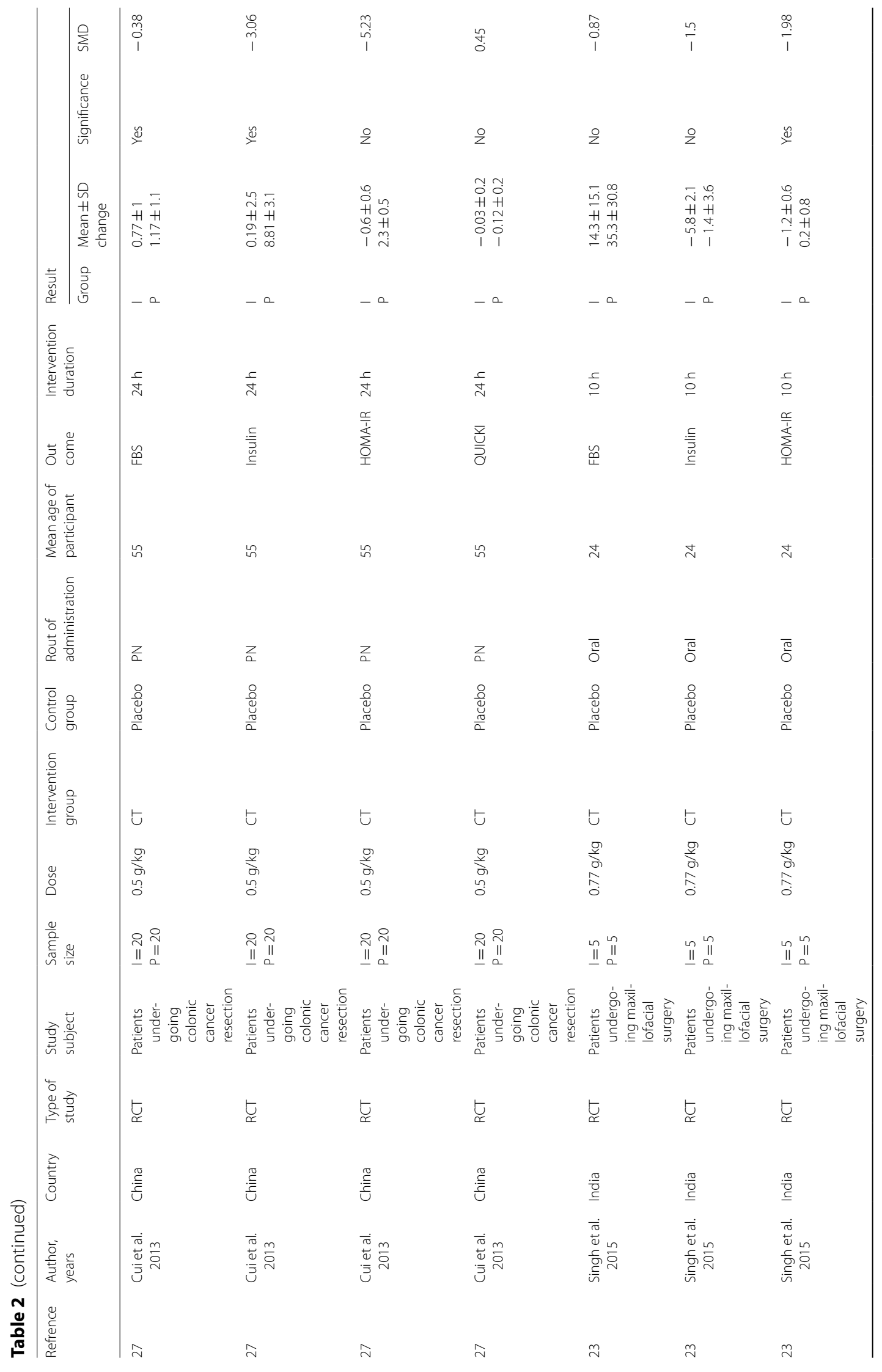




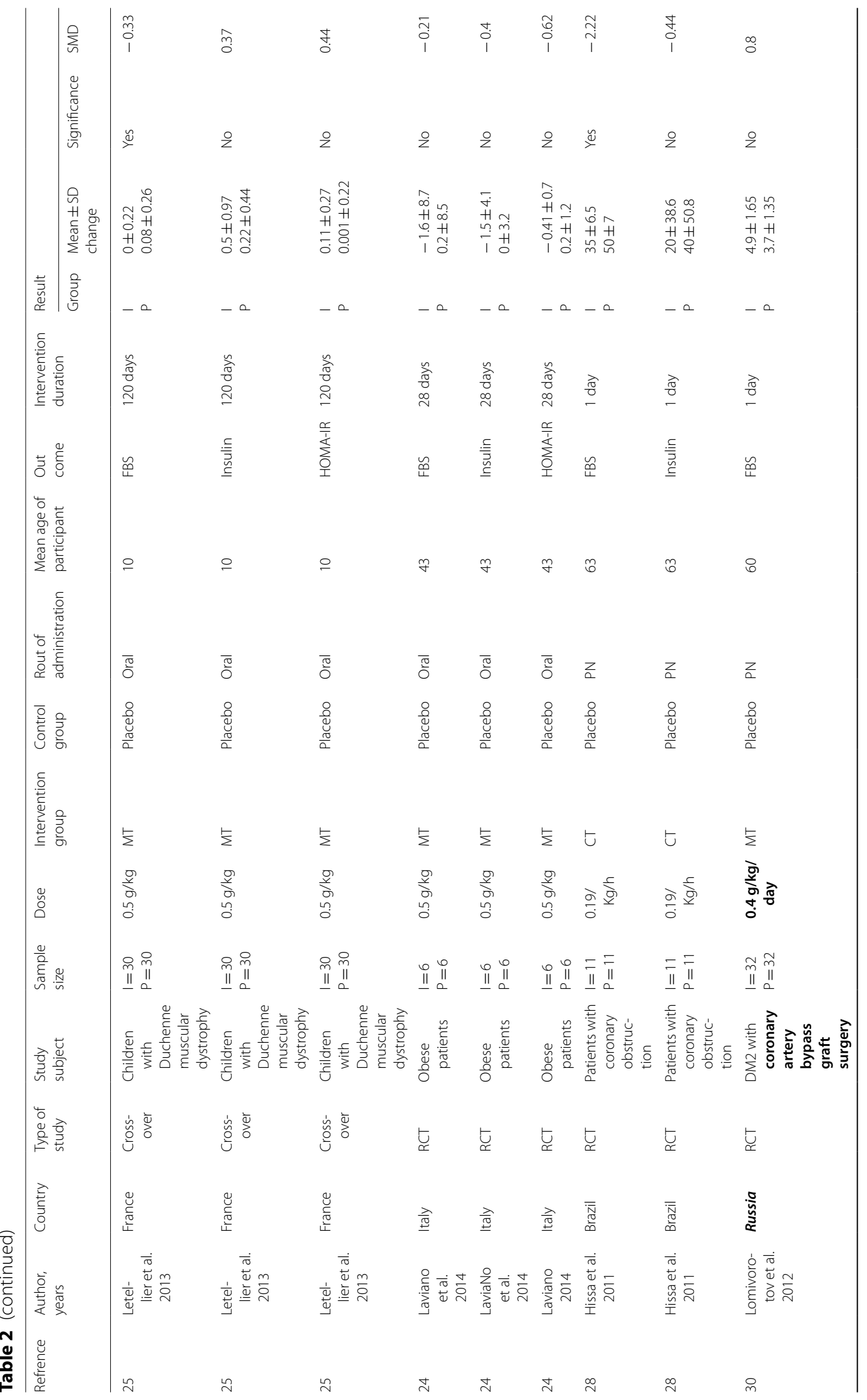




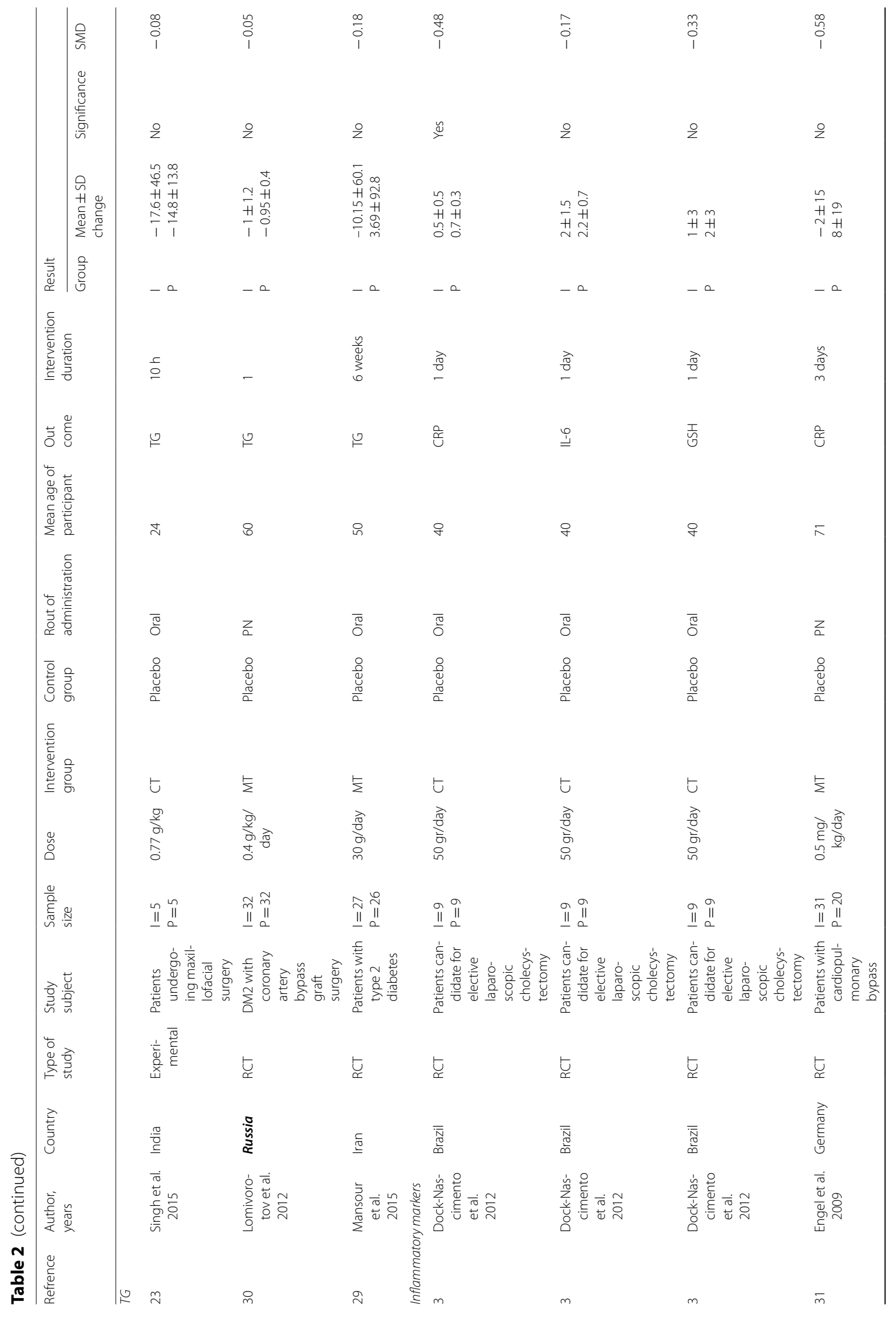




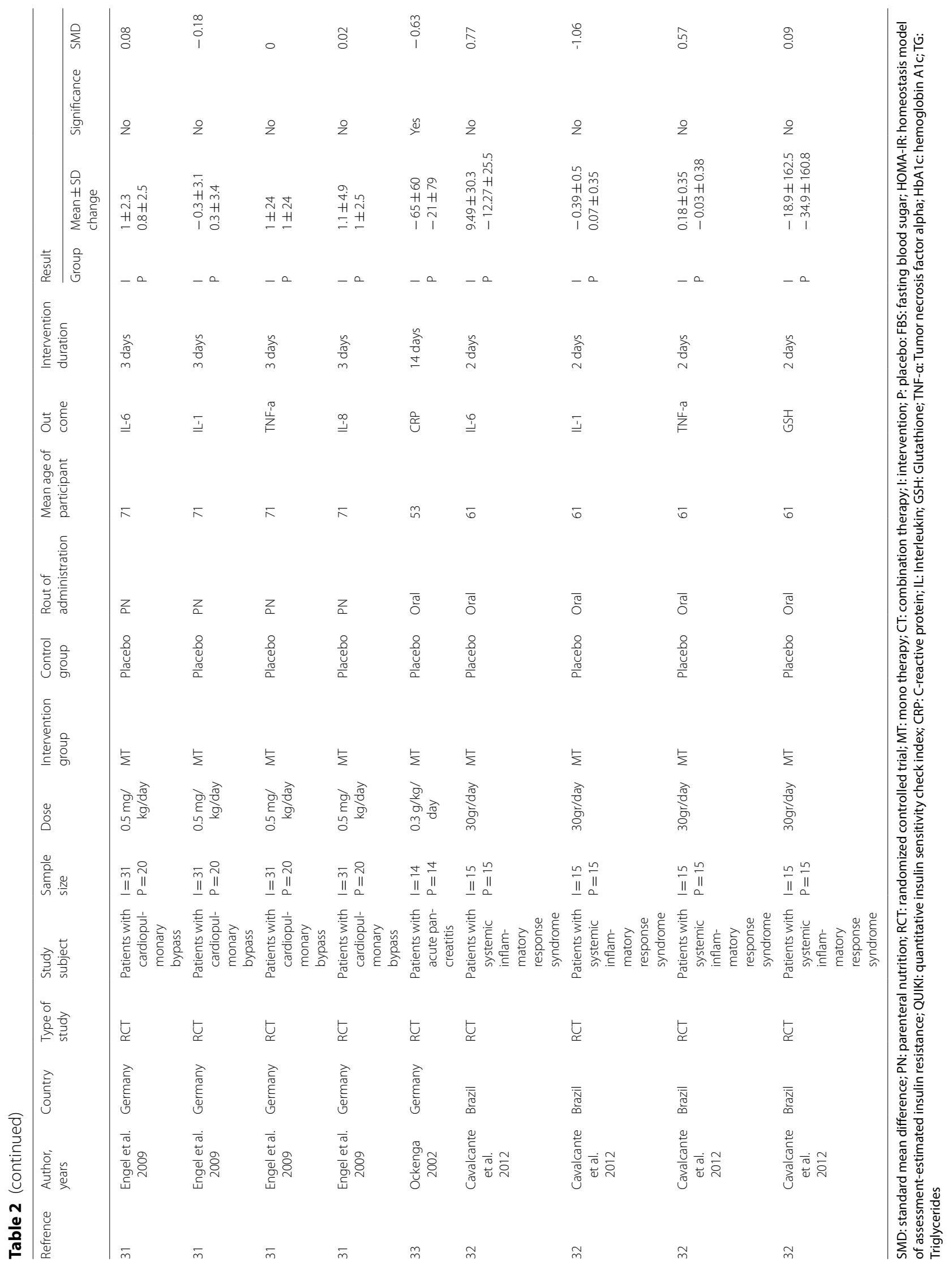


[25]. All studies were the double blind, placebo-controlled trials.

Subjects with maxillofacial surgery [23], patients with obesity and overweight [24], patients with Duchene Muscular Dystrophy [25], multiple trauma patients [26], patients with colon cancer resection [27], type 2 diabetes [29], patients with laparoscopic cholecystectomy [3], heart surgery patients [28], patients with SIRS \& sepsis[32], patients under cardiopulmonary bypass[31], patients with acute pancreatitis[33] and patients with type 2 diabetes under coronary artery bypass surgery[30] were en enrolled in the studies. There are no studies that have evaluated the effect of glutamine supplementation on hypertension.

\section{Glutamine supplementation and glycemic indices}

From 12 studies, nine RCTs including 249 participants in the glutamine or placebo groups reported FPG and 7 studies with 185 participants reported insulin as the outcome at baseline and follow-up. Five studies with 118 participants reported HOMA-IR, and 3 RCT with 129 participants reported QUIKI.

Meta-analyses suggested that intake of glutamine compared with placebo resulted in a statistically significant improvement in FPG [pooled standardized mean difference $[(\mathrm{SMD}):-0.73,95 \% \mathrm{CI}(-1.35,-0.11)]$ with obvious heterogeneity $\left(\mathrm{Q}=50.17 ; P=0.0 ; \mathrm{I}^{2} \%=78.4\right)$.

There were no significant improvements on glycemic indices such as Insulin, [(SMD): $-0.75,95 \%$ CI $(-1.65$, $0.15)]$ with obvious heterogeneity $(\mathrm{Q}=51.52 ; P=0.0$; $\left.\mathrm{I}^{2} \%=88.4\right)$, HOMA-IR [(SMD): $-1.38,95 \%$ CI $(-2.92$, $0.15)]$ with obvious heterogeneity $(\mathrm{Q}=66.78 ; P=0.0$; $\left.\mathrm{I}^{2} \%=94\right)$, QUIKI [(SMD): $0.241,95 \%$ CI $\left.(-0.13,0.62)\right]$ with obvious heterogeneity $\left(\mathrm{Q}=1.54 ; P=0.46 ; \mathrm{I}^{2} \%=0.0\right)$. Subgroup analysis based on rout of supplementation showed that glutamine significantly reduced FPG in oral supplementation of glutamine [(SMD): $-0.56,95 \% \mathrm{CI}$ $(-0.89,-0.23)]$ while the studies which used glutamine supplementation in parenteral way didn't show this effect on FPG [(SMD): $-0.16,95 \%$ CI $(-0.48,0.16)]$. Also, in this analysis we observed that glutamine supplementation in parenteral way significantly reduced Insulin [(SMD): $-1.63,95 \%$ CI $(-2.26,-1.01)]$ and HOMA-IR [(SMD): $-5.21,95 \%$ CI $(-6.58,-3.92)]$. No significant differences were found in subgroup analyzed based on rout of supplementation with respect to the effect of glutamine on QUIKI (Table 3). Pooled effect of glutamine supplementation on glycemic indices based on the rout of supplementation is presented in Figs. 2, 3, 4, 5.

\section{Glutamine supplementation and level of Triglyceride}

Pooled effect size based on 3 studies, including 127 participants, indicated that glutamine supplementation did not significantly reduce serum levels of TG [(SMD): $-0.11,95 \%$ CI $(-0.46,0.24)]$ without obvious heterogeneity $\left(\mathrm{Q}=0.11 ; P=0.95 ; \mathrm{I}^{2} \%=0.0\right)$. Subgroup analyzed based on rout of supplementation didn't show any differences in the effect of glutamine on TG (Fig. 6).

\section{Glutamine supplementation and inflammatory markers}

Pooling effect sizes from 4 publications, including 126 participants, we found that glutamine supplementation had a significant effect on CRP [(SMD): $-0.58,95 \%$ CI $(-0.1,-0.17)]$ without obvious heterogeneity $(\mathrm{Q}=0.06$; $\left.P=0.97 ; \quad \mathrm{I}^{2} \%=0.0\right)$ while there were no significant effects of glutamine supplementation on IL-6 [(SMD): $0.24,95 \%$ CI $(-0.16,0.64)]$ without obvious heterogeneity $\left(\mathrm{Q}=3.05 ; P=0.22 ; \mathrm{I}^{2} \%=34.5\right)$, GSH $[(\mathrm{SMD}):-0.06$, 95\% CI $(-0.63,0.51)]$ without obvious heterogeneity $\left(\mathrm{Q}=0.52 ; P=0.47 ; \mathrm{I}^{2} \%=0.0\right)$, IL-1 [(SMD): $-0.58,95 \%$ CI $(-1.44,0.27)]$ with obvious heterogeneity $(\mathrm{Q}=3.27$; $\left.P=0.07 ; \mathrm{I}^{2} \%=69.5\right)$ and TNF- $\alpha[(\mathrm{SMD}): 0.21,95 \% \mathrm{CI}$ $(-0.23,0.66)]$ without obvious heterogeneity $(\mathrm{Q}=1.49$; $\left.P=0.22 ; \mathrm{I}^{2} \%=33.0\right)$.

In subgroup analyzed based on the rout of supplementation, we observed that the oral glutamine supplementation significantly reduced IL-1 [(SMD): $-1.06,95 \% \mathrm{CI}$ $(-1.83,-0.30)]$ and glutamine supplementation in a parenteral way reduced CRP [(SMD): $-0.06,95 \%$ CI $(-1.17$, $0.025)]$ while this result dod not observe in orally glutamine supplementation (Figs. 7, 8, 9, 10, 11).

\section{Quality assessment}

Based on the Cochrane quality assessment tool, 4 trials were classified as good quality and the rest of the studies were classified as fair and poor quality. Among the 12 randomized controlled trials, the main issues were a high risk of bias due to lack of blinding of participants and study personnel and lack of blinding of outcome assessment. Details of the risk of bias assessment for included trials are presented in Table 4.

\section{Meta-regression}

The effect of influencing factors was analyzed using a random-effect meta-regression. There was no effect of influencing factors, such as duration, mean age, dose, the rout of administration, type of indices and female ration on the heterogeneity of glycemic indexes such as FPG, Insulin, HOMA-IR, HBA1C, TG, and inflammatory markers such as CRP, IL-6, GSH, IL-1 and TNF- $\alpha(P>0.05)$.

\section{Publication bias}

Publication bias was estimated by Egger's test. The results of Egger's test did not support the existence of publication bias by glutamine supplementation on Insulin (coefficient $=-5.53, \mathrm{P}=0.08$ ), HOMA-IR (coefficient $=-6.78$, 
$\mathrm{P}=0.11$ ), QUIKI (coefficient $=2.48, \mathrm{P}=0.47)$, TG (coefficient $=0.008, P=0.99$ ) and inflammatory markers (coefficient $=-0.88, \mathrm{P}=0.67$ ).

The results of Egger's test supported the existence of publication bias by glutamine supplementation on FPG (coefficient $=-4.60$, standard error $=1.82, \mathrm{P}=0.04,95 \%$ $\mathrm{CI}-8.9,-0.29)$. The funnel plot of standard error versus effect size (mean difference) was slightly asymmetric The trim-and-fill correction suggested three potentially missing studies on the left side of the funnel plot. Imputation for this potentially missing study yielded an effect size of -1.08 (95\% CI - 1.85, - 0.31).

\section{Discussion}

This is one of the first reviews summarizing randomized controlled trials (RCTs) that aimed to bring together the results of all eligible RCTs to gauge the influence of glutamine supplementation on glucose, insulin metabolism, lipid profile, and inflammatory factors.

In this study as a whole, glutamine supplementation reduced FPG as compared with placebo. In an attempt to address the effect of the route of the supplementation, oral versus parenteral trials included in the systematic review, we performed subgroup analyses to examine the role of these factors. We observed a more significant reduction of FPG for oral GLN. Combining all studies, no significant effects of glutamine supplementation on the parameters of insulin, HOMA-IR, and QUIKI were observed. Including only studies with parenteral glutamine supplementation revealed a significant effect of glutamine supplementation on insulin and HOMA-IR. We investigated the efficacy of glutamine therapy (oral and/or intravenous) in the inflammatory factors and found that both oral and intravenous glutamine supplementation reduced hs-CRP. Parenteral glutamine supplementation was more effective in improving hs-CRP levels, but neither route reduced other inflammatory factors.

Interestingly, the beneficial effect of GLN on IL-1 was greater in the oral use of supplementation than the parenteral glutamine supplementation. The main challenge of this systematic review was the heterogeneity between the studies with GLN supplementation in the dose of regimens of glutamine, much broader populations including non-critically ill patients (obesity, type 2 diabetes), or specific populations (acute pancreatitis, SIRS \& sepsis or surgery) and methods of administration used in the included studies. Our present analysis could not find strong signals of publication bias effects on the insulin levels and insulin resistance, lipid profile, and inflammatory factors except for FPG.

Until recently, hyperglycemia in patients without a history of diabetes mellitus has often been viewed as an adaptive phenomenon caused by increased levels of counter-regulatory hormones, cytokines, and insulin resistance during periods of stress and decreased peripheral glucose use of tissues, mainly skeletal muscle and enhanced glucose production [28]. It has been described as "stress" hyperglycemia, and appears to be a marker for severity of disease in critically ill patients [34], and is strongly associated with an increased risk of mortality and morbidity among such patients [35]. It can be assumed that glutamine promotes in incretin hormone glucagon-like protein-1 (GLP-1) secretion from intestinal L-cells [16], and GLP-1 like the other incretins, is secreted from the gut in response to binding nutrients to the receptors and can stimulate insulin secretion [36]. The beneficial effects seem to be glucose-dependent insulin secretion and insulin action, providing a mechanism for the effects of oral glutamine on glycemic control [37, 38]. Independent of increasing insulin secretion, GLP-1 activation can increase the gastric emptying time and is thought to be the main cause of reduced glycemia in the glutamine [39]. In our meta-analysis, data showed no rise in insulin levels with oral admiration of glutamine.

We did not observe a clear difference in insulin levels or insulin sensitivity after glutamine administration. However, in the subgroup analysis, the effect of glutamine administration on insulin sensitivity improvement was seen in trials that glutamine delivered by the parenteral route. This may be due to the various methods of administration and delivery and different intervention population. It should be noted that only two ials involving glutamine by parental route were included in this subgroup analysis, and in both studies, the dipeptide of glutamine was used. Variations in supplementation protocol may be more important in determining the efficacy of glutamine supplementation than volunteers' characteristics. It is unclear whether the attenuation of insulin resistance effect of glutamine is partly due to alanine. Additionally, recent studies found that serum glutamine concentrations were closely related to insulin sensitivity in glutamine supplemented people; most likely due to the IV route of delivery much higher plasma glutamine concentrations may be achieved [40].

There are several plausible biological mechanisms by which glutamine may affect serum lipid profile. Glutamine has been shown to increase the absorption of triacylglycerol in the intestine of rats [41]. On the other hand, glutamine reduces lipid absorption due to increased GLP-1 levels [42]. In our meta-analysis, only three trials involving glutamine effects on lipid profile have been identified. Despite its effect on absorption and GLP-1 levels, our data showed that glutamine had no effects on TG levels. 
Table 3 Meta-analysis of effect of glutamine supplementation on glycemic indices, triglyceride and inflammatory markers

\begin{tabular}{|c|c|c|c|c|c|c|c|}
\hline & \multirow[t]{2}{*}{ No. of study } & \multirow[t]{2}{*}{ Pooled SMD (95\% Cl) } & \multirow[t]{2}{*}{$P$ value } & \multicolumn{3}{|c|}{ Heterogeneity assessment } & \multirow{2}{*}{$\begin{array}{l}\text { P for between } \\
\text { subgroup } \\
\text { heterogeneity }\end{array}$} \\
\hline & & & & $1^{2}$ & Q test & $P$ value & \\
\hline \multicolumn{8}{|l|}{ FBS } \\
\hline Oral & 5 & $-0.56(-0.89,-0.23)^{*}$ & 0.001 & 75.8 & 16.54 & 0.002 & 0.088 \\
\hline PN & 4 & $-0.16(-0.48,0.16)$ & 0.33 & 90.2 & 30.72 & $<0.001$ & \\
\hline Total & 9 & $-0.73(-1.35,-0.11)^{*}$ & 0.02 & 84.1 & 50.17 & $<0.001$ & \\
\hline \multicolumn{8}{|c|}{ Insulin } \\
\hline Oral & 5 & $0.07(-.25,0.39)$ & 0.66 & 67.3 & 12.23 & 0.016 & $<0.001$ \\
\hline PN & 2 & $-1.63(-2.26,-1.01)^{*}$ & $<0.001$ & 94.0 & 16.71 & $<0.001$ & \\
\hline Total & 7 & $-0.75(-1.65,0.15)$ & 0.10 & 88.4 & 51.52 & $<0.001$ & \\
\hline \multicolumn{8}{|c|}{ HOMA-IR } \\
\hline Oral & 4 & $0.04(-0.3,0.39)$ & 0.8 & 69.9 & 9.97 & 0.019 & $<0.001$ \\
\hline PN & 1 & $-5.21(-6.58,-3.92)^{*}$ & $<0.001$ & - & - & - & \\
\hline Total & 5 & $-1.38(-2.92,0.15)$ & 0.07 & 94 & 66.78 & $<0.001$ & \\
\hline \multicolumn{8}{|l|}{ QUIKI } \\
\hline Oral & 2 & $0.13(-0.34,0.6)$ & 0.59 & 0.0 & 0.90 & 0.34 & 0.42 \\
\hline PN & 1 & $0.45(-.18,1.08)$ & 0.16 & - & - & - & \\
\hline Total & 3 & $0.24(-0.13,0.62)$ & 0.20 & 0.0 & 1.54 & 0.46 & \\
\hline \multicolumn{8}{|l|}{$T G$} \\
\hline Oral & 2 & $-0.16(-0.65,0.33)$ & 0.52 & 0.0 & 0.02 & 0.89 & - \\
\hline PN & 1 & $-0.05(-0.54,0.43)$ & - & - & - & - & \\
\hline Total & 3 & $-0.11(-0.46,0.24)$ & 0.54 & 0.0 & 0.11 & 0.94 & \\
\hline \multicolumn{8}{|l|}{$C R P$} \\
\hline Oral & 2 & $-0.57(-1.16,0.02)$ & 0.058 & 0.0 & 0.05 & 0.82 & $<0.001$ \\
\hline PN & 1 & $-0.6(-1.17,-0.025)^{*}$ & - & - & - & - & \\
\hline Total & 3 & $-0.58(-0.1,-0.17)^{*}$ & 0.005 & 0.0 & 0.06 & 0.97 & \\
\hline \multicolumn{8}{|l|}{ IL-6 } \\
\hline Oral & 2 & $0.40(-0.17,0.98)$ & 0.17 & 59.1 & 2.45 & 0.12 & - \\
\hline PN & 1 & $0.084(-0.48,0.64)$ & - & - & - & - & \\
\hline Total & 3 & $0.24(-0.16,0.64)$ & 0.24 & 34.5 & 3.05 & 0.22 & \\
\hline \multicolumn{8}{|l|}{ GSH } \\
\hline Oral & 2 & $-0.06(-0.63,0.51)$ & 0.83 & 0 & 0.52 & 0.47 & - \\
\hline \multicolumn{8}{|l|}{ IL-1 } \\
\hline Oral & 1 & $-1.06(-1.83,-0.30)^{*}$ & - & - & - & - & - \\
\hline PN & 1 & $-0.18(-0.75,0.38)$ & - & - & - & - & \\
\hline Total & 2 & $-0.58(-1.44,0.27)$ & 0.18 & 69.5 & 3.27 & 0.07 & \\
\hline \multicolumn{8}{|c|}{ TNF- $a$} \\
\hline Oral & 1 & $0.57(-0.15,1.31)$ & - & - & - & - & - \\
\hline PN & 1 & $0.0(-0.56,0.56)$ & - & - & - & - & \\
\hline Total & 2 & $0.21(-0.23,0.66)$ & 0.35 & 33.0 & 1.49 & 0.22 & \\
\hline
\end{tabular}

*Statistically significant

PN: parenteral nutrition; FBS: fasting blood sugar; HOMA-IR: homeostasis model of assessment-estimated insulin resistance; QUIKI: quantitative insulin sensitivity check index; CRP: C-reactive protein; IL: Interleukin; GSH: Glutathione; TNF-a: Tumor necrosis factor alpha; HbA1c: hemoglobin A1c; TG: Triglycerides

Data from pre-clinical and clinical studies suggest that glutamine induces inflammation mechanism and oxidative damage through heat shock protein 70 (HSP70) release $[43,44]$ and glutathione (GSH) pathway, a critical antioxidant $[45,46]$, respectively. The beneficial effects of glutamine during critical illness are mainly related to its anti-inflammatory property rather than antioxidant effects [17]. Four trials investigatng the effect of glutamine on inflammatory factors met the full inclusion criteria. Our analysis found evidence of hs-CRP reduction by supplementation with glutamine. Subgroup analyses found evidence of a hs-CRP reduction in patients 


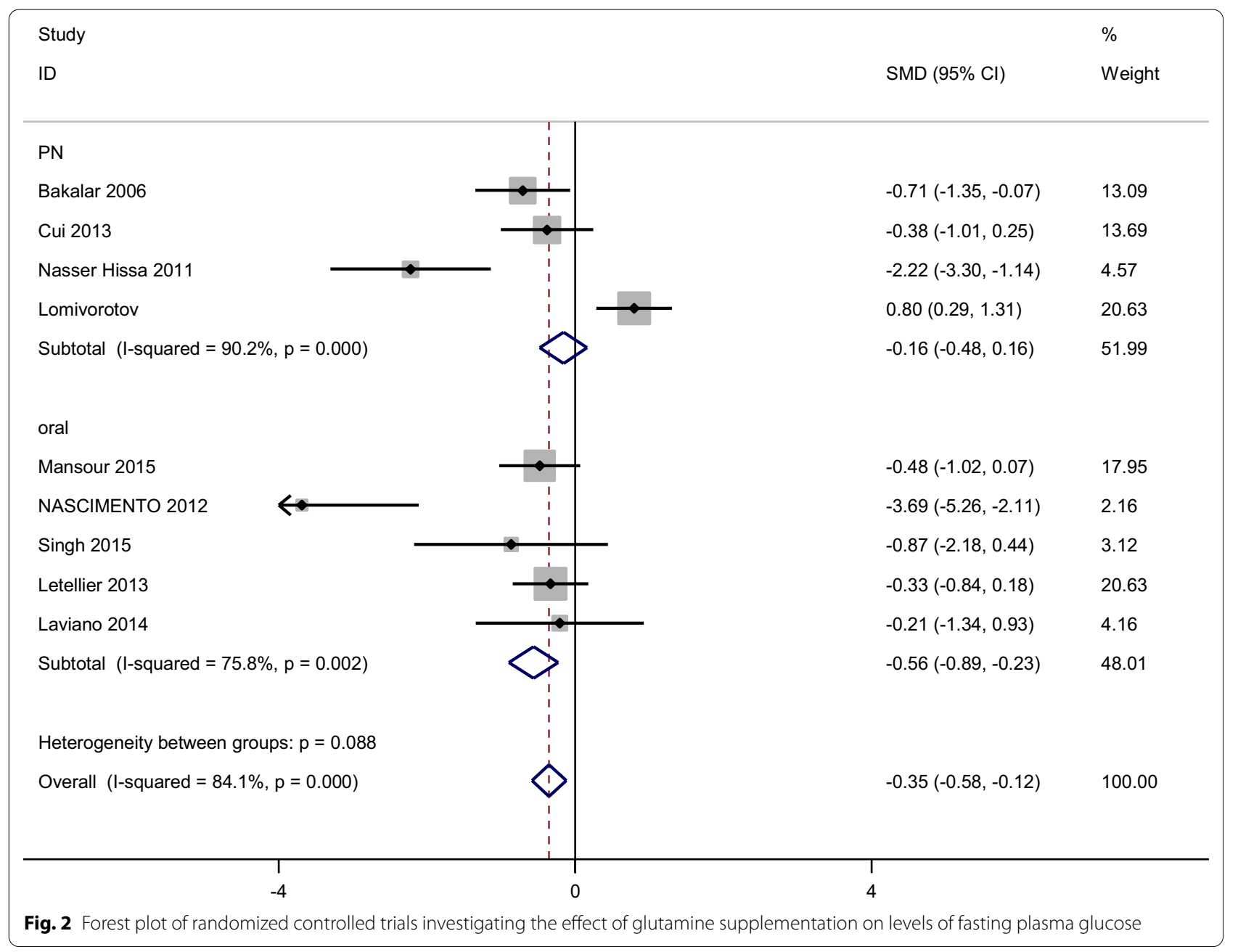

with parenteral use of glutamine. In addition, we found a relationship between the effects of oral supplementation on IL-1 levels. However, findings of this meta-analysis did not show a statistically significant impact of glutamine supplementation on other selected pro-inflammatory cytokines (TNF- $\alpha$ and IL-6).

It is important to note that the controversial results may come from the variations in several factors and may affect the interpretation of glutamine's role on metabolic factors [47]. Some of these differences may be attributed to variations in the option of glutamine delivery, including oral and parenteral route; we showed that different outcomes might derived from the glutamine different administration route of delivery. Possibly, the results obtained from this study may be related to this phenomenon. This variation can, for example, affectplasma levels of glutamine; however, both parenteral and enteral glutamine administration lead to significant increases in plasma glutamine concentration, the metabolic pathway of glutamine into citrulline and arginine is affected by the route of administration, and there is a greater increase in plasma arginine when is given parenterally [48]. Another example is variation in glutamine administration forms (free or dipeptide) in the different route of administration; Free Glutamine is not a component of parenteral amino acid solutions because of its poor aqueous solubility and easily hydrolyzed to glutamic acid and NH4 when compared to dipeptide form. The use of glutaminecontaining dipeptides such as the dipeptide L-alanyl-Lglutamine is a good alternative and has more availability and beneficial effects than free amino acids an area of research that needs to be tested in human subjects [45, 49]. Another important note is the wide range of clinical trials conducted on different doses of glutamine supplementation (from fixed dose of 20-35 g/d to adjusted dose of $<0.1 \mathrm{~g} / \mathrm{kg}$ body weight $/ \mathrm{d}$ ) [50] which did not reach consensus on the best supplementation regime to normalize plasma glutamine concentration without increasing glutamate levels. However, in a study conducted by Nageli et al., a high-dose glutamine supplementation 


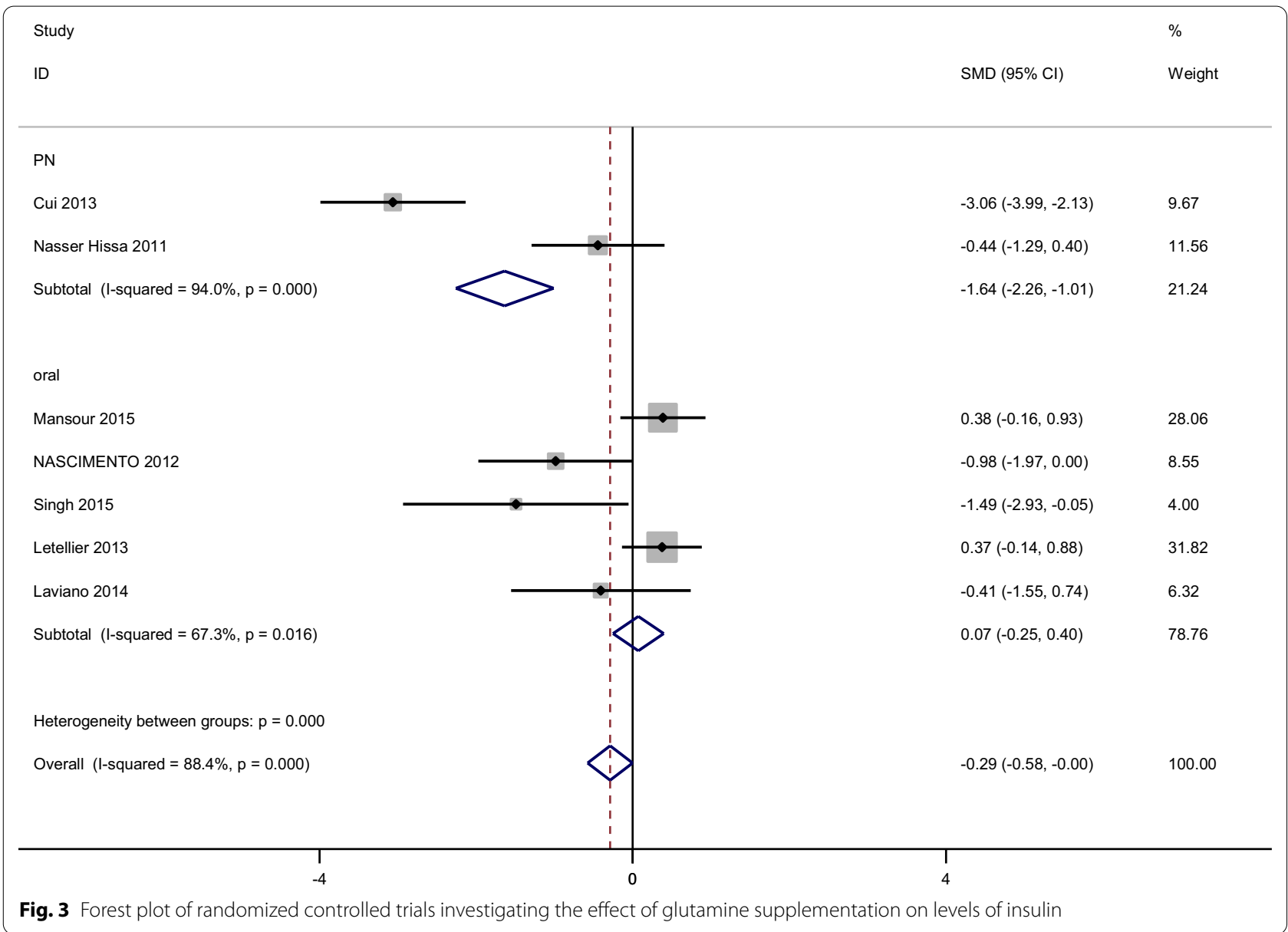

$(0.75 \mathrm{~g} / \mathrm{kg} / \mathrm{d})$ is thought to lead to increase in glutamine pool without a sign of potential glutamate-mediated cerebral injury. Nowadays, glutamine deficiency is commonly defined by low plasma glutamine levels [51]. The debate continues as to what level of glutamine supplementation is necessary to achieve optimal effects [52]. However, in part, all studies were not included in this meta-analysis, which had targeted patients with the lowest circulating glutamine levels. Another possibility is that glutamine level is a consequence [38], rather than a cause of disease or disease precursor states; It has been shown that critical illnesses, such as trauma, burn and sepsis are associated with acutely both intramuscular and circulating glutamine depletion [53] On the other hand,, plasma glutamine may be increased in some of conditions such as hepatic failure and renal dysfunction [47].

\section{Limitations}

The limitations of our study need to be mentioned. The included studies were almost all single-center trials, and most were of small to moderate sample size; this has not been clarified and confirmed in properly powered trials. While some effects on metabolic and inflammatory factors were detected, subgroup analysis was mainly explored, and the size of the observed effect was modest. The target population of included trials was relatively different, and we could not perform subgroup meta-analysis according to the study population. Therefore the findings should be interpreted cautiously. Another limitation is the small number of trials that have specifically targeted patients with low glutamine levels at baseline; such patients may be more likely to respond to glutamine interventions. Due to time constraints, this study does not have the protocol registered in the International Prospective Register of Systematic Reviews.

\section{Conclusion}

In this meta-analysis, we found a beneficial effect in improving the clinical outcomes after glutamine supplementation in various diseases. Our subgroup analysis comparing oral and parenteral routs of administration showed varied results; however, this characteristic modifing the treatment effects has not been sufficiently studied for glutamine. Future well-controlled and 


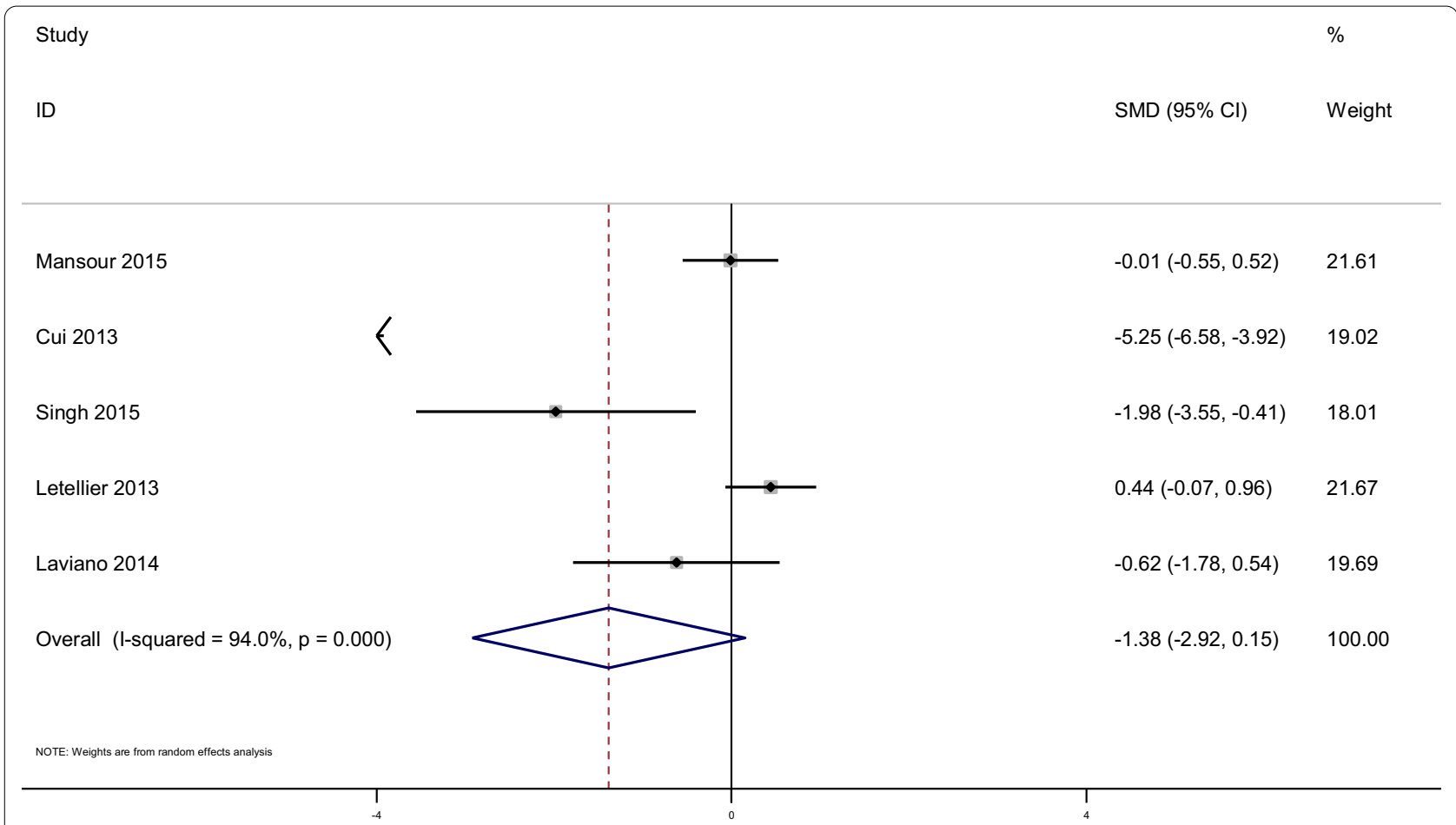

Fig. 4 Forest plot of randomized controlled trials investigating the effect of glutamine supplementation on levels of HOMA-IR

Study

ID

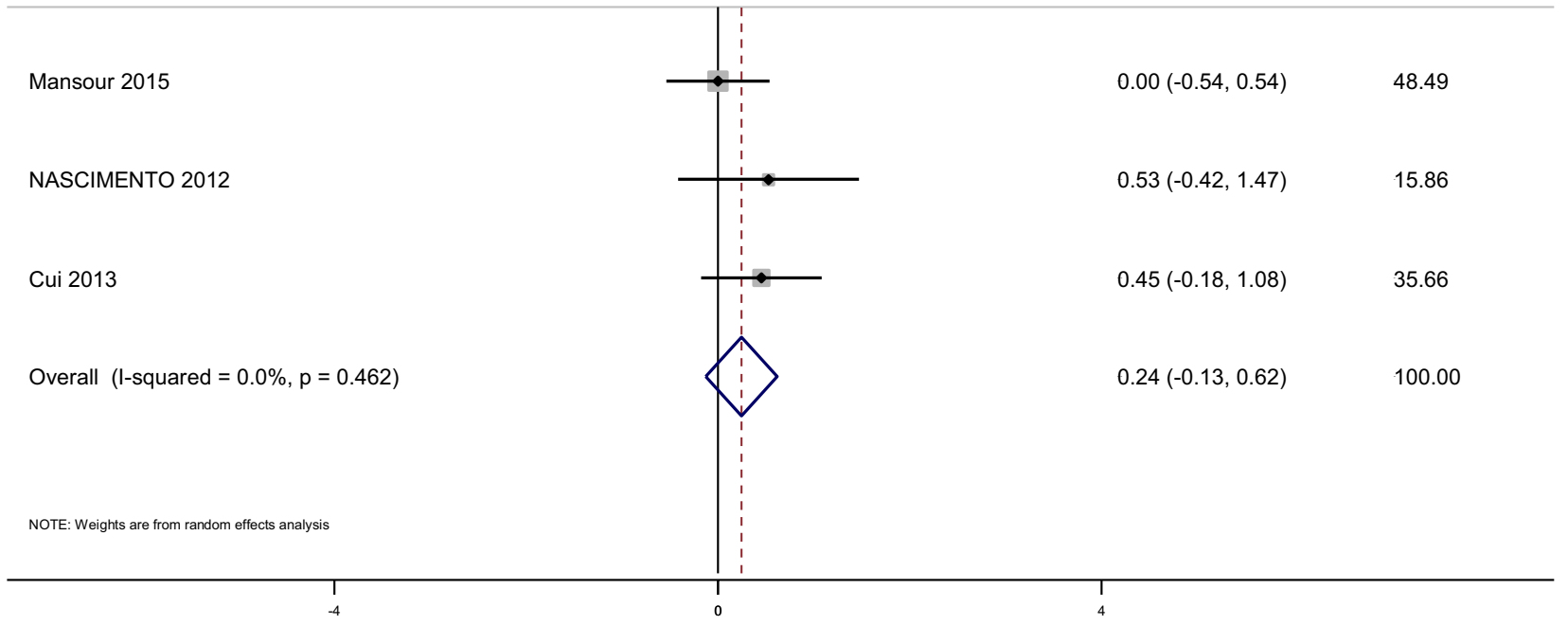

Fig. 5 Forest plot of randomized controlled trials investigating the effect of glutamine supplementation on levels of QUIKI

$\%$

Weight

$\operatorname{SMD}(95 \% \mathrm{Cl}) \quad$ Weight




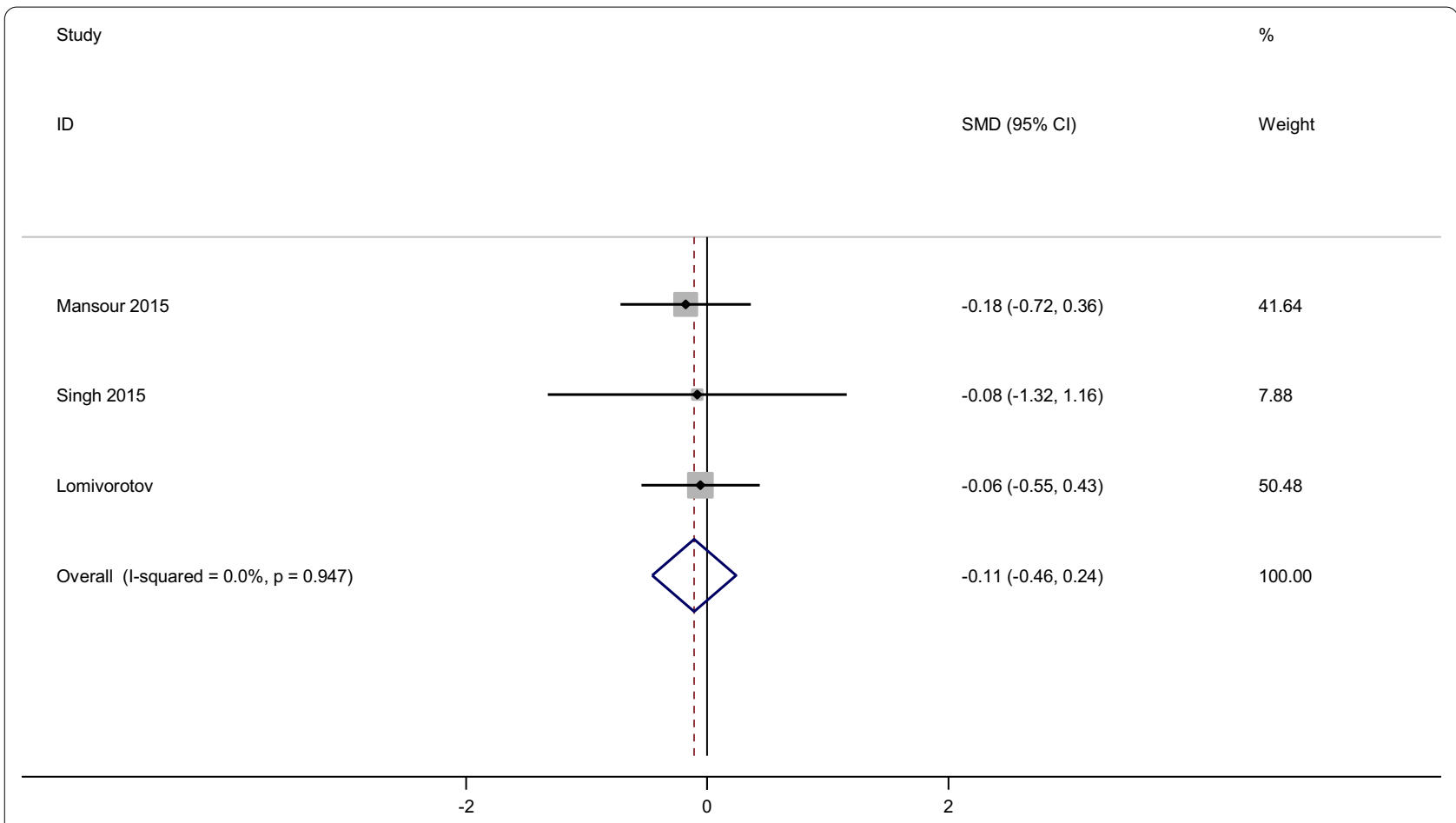

Fig. 6 Forest plot of randomized controlled trials investigating the effect of glutamine supplementation on levels of triglyceride

$$
\text { Study }
$$

ID

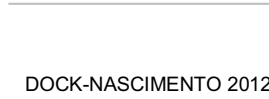

Engel 2009

OCKENGA 2002

Overall $(\mathrm{I}$-squared $=0.0 \%, p=0.971)$
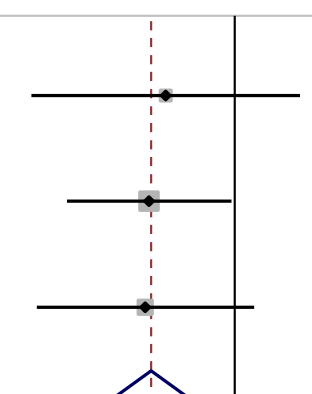

SMD $(95 \% \mathrm{Cl})$

Weight

\begin{tabular}{lc}
$-0.49(-1.42,0.45)$ & 19.24 \\
$-0.60(-1.17,-0.03)$ & 51.40 \\
$-0.63(-1.39,0.13)$ & 29.36 \\
$-0.59(-1.00,-0.17)$ & 100.00 \\
\hline
\end{tabular}

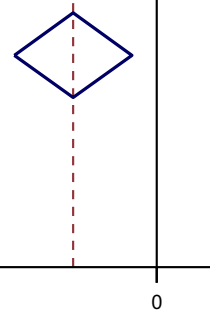

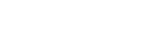


Study

ID

DOCK-NASCIMENTO 2012

Engel 2009

Cavalcante 2012

Overall $(I-s q u a r e d=34.5 \%, p=0.217)$

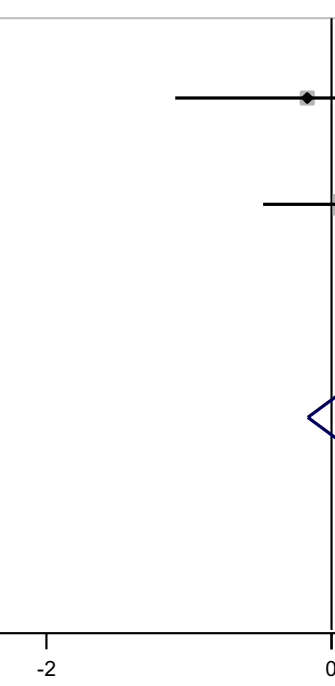

$\operatorname{SMD}(95 \% \mathrm{Cl})$

Weight

$\%$

$\begin{array}{ll}-0.17(-1.10,0.75) & 19.02 \\ 0.08(-0.48,0.65) & 51.54 \\ 0.78(0.03,1.52) & 29.44 \\ 0.24(-0.16,0.64) & 100.00\end{array}$

Fig. 8 Forest plot of randomized controlled trials investigating the effect of glutamine supplementation on levels of IL-6

Study

ID

DOCK-NASCIMENTO 2012

Cavalcante 2012

Overall (I-squared $=0.0 \%, p=0.471$ )

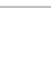
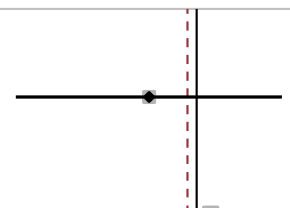

$-0.33(-1.26,0.60)$

37.17

$0.10(-0.62,0.82)$

62.83

$-0.06(-0.63,0.51)$

100.00
$\%$

Weight

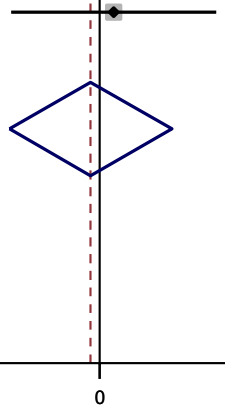

\section{$-0.06(-0.63,0.51)$}

Weight




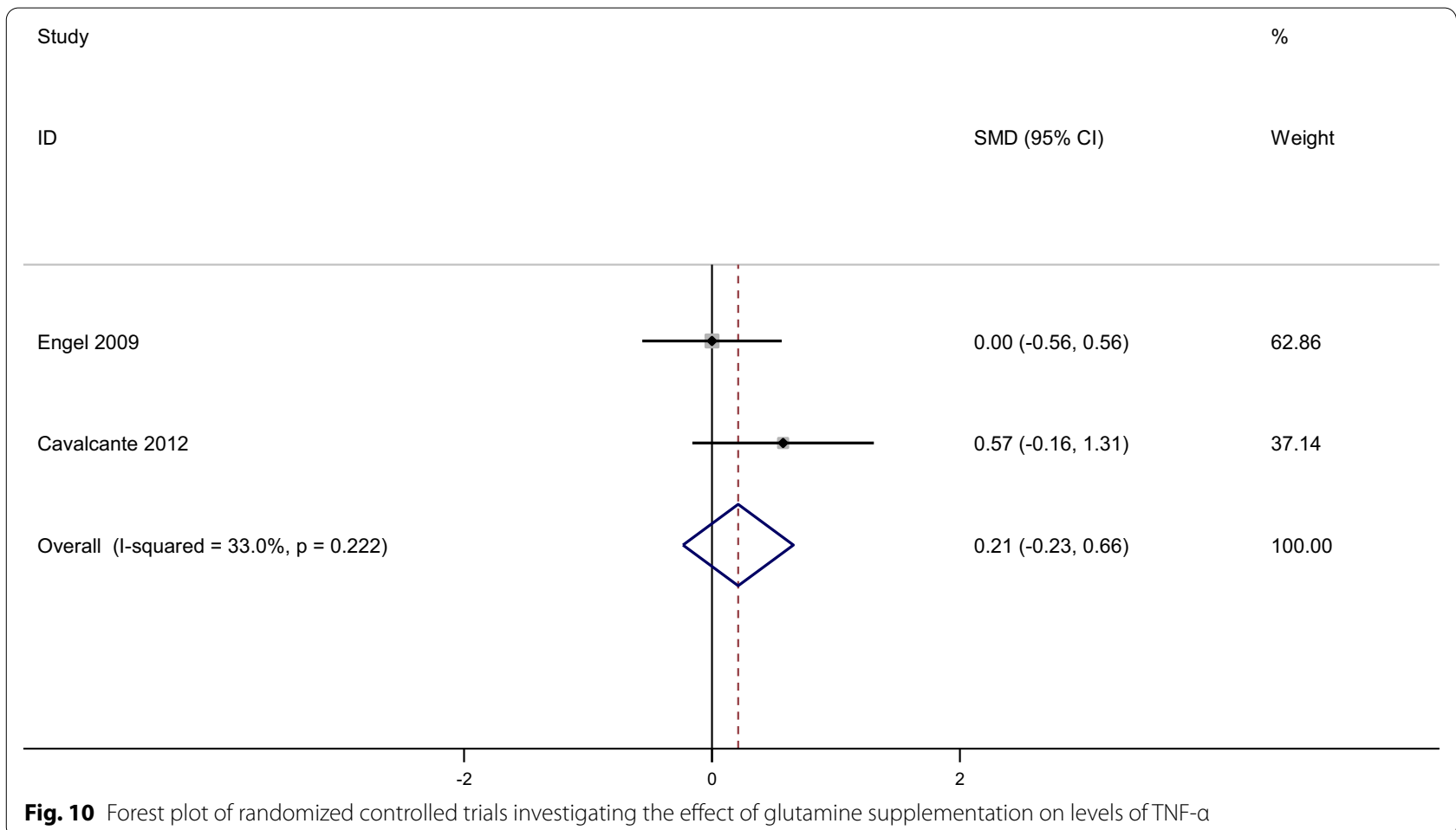

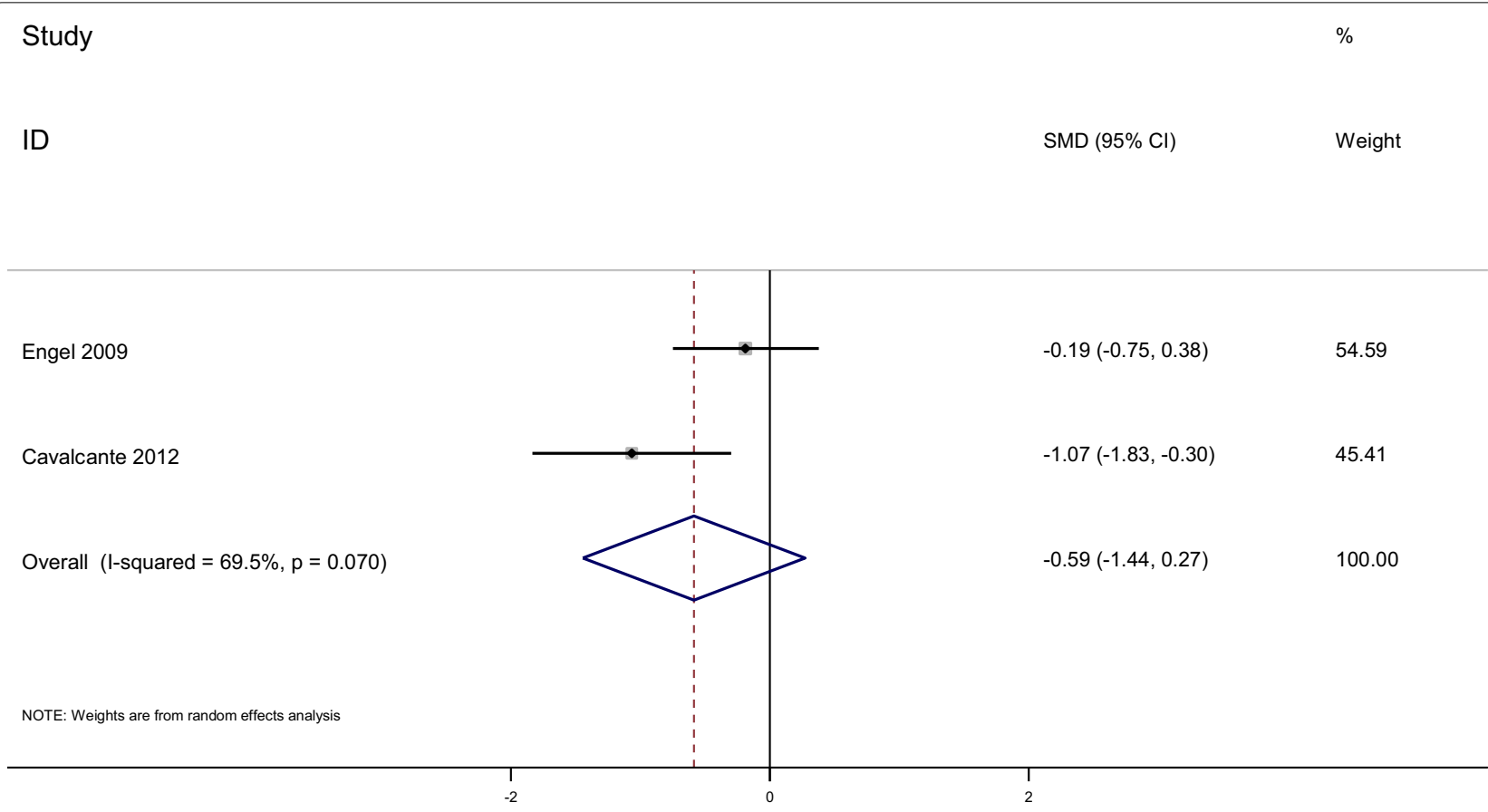

Fig. 11 Forest plot of randomized controlled trials investigating the effect of glutamine supplementation on levels of IL-1 
Table 4 Risk of bias assessment in randomized controlled trials

\begin{tabular}{|c|c|c|c|c|c|c|c|c|c|}
\hline \multirow[t]{2}{*}{ Author (year) } & \multirow[t]{2}{*}{$\begin{array}{l}\text { Sequence } \\
\text { generation }\end{array}$} & \multirow[t]{2}{*}{$\begin{array}{l}\text { Allocation } \\
\text { concealment }\end{array}$} & \multirow{2}{*}{$\begin{array}{l}\text { Blinding of } \\
\text { participants } \\
\text { and } \\
\text { personnel }\end{array}$} & \multicolumn{2}{|c|}{$\begin{array}{l}\text { Blinding of outcome } \\
\text { assessors }\end{array}$} & \multirow{2}{*}{$\begin{array}{l}\text { Incomplete } \\
\text { outcome } \\
\text { data }\end{array}$} & \multirow[t]{2}{*}{$\begin{array}{l}\text { Selective } \\
\text { reporting }\end{array}$} & \multirow[t]{2}{*}{ Other bias } & \multirow[t]{2}{*}{ Overall quality } \\
\hline & & & & $\begin{array}{l}\text { Subjective } \\
\text { outcomes }\end{array}$ & $\begin{array}{l}\text { Objective } \\
\text { outcomes }\end{array}$ & & & & \\
\hline $\begin{array}{c}\text { Bakalar et al. } \\
2006 \text { [26] }\end{array}$ & Low risk & Unclear risk & High risk & High risk & Unclear risk & Low risk & Low risk & Unclear risk & Poor quality \\
\hline $\begin{array}{l}\text { Mansour et al. } \\
2015 \text { [29] }\end{array}$ & Low risk & Low risk & Unclear risk & High risk & Unclear risk & Low risk & Low risk & Low risk & Poor quality \\
\hline $\begin{array}{l}\text { Dock-Nasci- } \\
\text { mento et al. } \\
2012 \text { [3] }\end{array}$ & Low risk & Low risk & Unclear risk & Unclear risk & Low risk & Low risk & Low risk & Low risk & Fair quality \\
\hline $\begin{array}{l}\text { Cui et al. } 2013 \\
\text { [27] }\end{array}$ & Low risk & Low risk & Low risk & Unclear risk & Low risk & Low risk & Low risk & Low risk & Good quality \\
\hline $\begin{array}{l}\text { Singh et al. } \\
2015 \text { [23] }\end{array}$ & Low risk & Unclear risk & High risk & High risk & Unclear risk & Low risk & Low risk & Low risk & Fair quality \\
\hline $\begin{array}{l}\text { Letellier et al. } \\
\qquad 2013 \text { [25] }\end{array}$ & Low risk & Low risk & Low risk & Low risk & Low risk & Low risk & Low risk & Low risk & Good quality \\
\hline $\begin{array}{l}\text { Laviano et al. } \\
\qquad 2014 \text { [24] }\end{array}$ & Low risk & Unclear risk & High risk & High risk & Unclear risk & Low risk & Low risk & Unclear risk & Poor quality \\
\hline $\begin{array}{l}\text { Hissa et al. } \\
2011 \text { [28] }\end{array}$ & Low risk & Unclear risk & High risk & Unclear risk & Unclear risk & Low risk & Low risk & Low risk & Poor quality \\
\hline $\begin{array}{l}\text { Engel et al. } \\
2009[31]\end{array}$ & Low risk & Low risk & Low risk & Unclear risk & Unclear risk & Low risk & Low risk & Low risk & Fair quality \\
\hline $\begin{array}{l}\text { Ockenga et al. } \\
2002 \text { [33] }\end{array}$ & Low risk & Low risk & Low risk & Low risk & Low risk & Low risk & Low risk & Low risk & Good quality \\
\hline $\begin{array}{l}\text { Cavalcante } \\
\text { et al. } 2012 \\
\text { [32] }\end{array}$ & Low risk & Low risk & Low risk & High risk & Unclear risk & Low risk & Low risk & Unclear risk & Poor quality \\
\hline $\begin{array}{l}\text { Lomivorotov } \\
\text { et al. } 2012 \\
\text { [30] }\end{array}$ & Low risk & Low risk & Low risk & Unclear risk & Low risk & Low risk & Low risk & Low risk & Good quality \\
\hline
\end{tabular}

well-randomized trials are needed to investigate the routes of glutamine administration which have the greatest potential for correction of metabolic abnormalities.

\section{Acknowledgements}

Not applicable.

\section{Authors' contributions}

All authors contributed to the conceptualization of the systematic review. AM and $\mathrm{FO}$ conducted the data sereaching. $\mathrm{MH}, \mathrm{ArM}$ and $\mathrm{HA}$ conducted the data screening and quality assessment. SD and $\mathrm{MH}$ conducted the data extraction and drafted the manuscript. MQ and HA performed meta-analysis and drafted the manuscript. All authors read and approved the final manuscript.

\section{Funding}

This study was supported by National Institute for Medical Research Development (NIMAD), Grant No. 971234

\section{Availability of data and materials}

No additional data are available.

\section{Declarations}

\section{Ethics approval and consent to participate}

This systematic review and meta-analysis study was not performed on both human or animal subjects. The Ethics council of National Institute for Medical Research Development (NIMAD), Tehran, Iran.

\section{Consent for publication}

Not applicable.

\section{Competing interests}

The authors declare that they have no competing interests.

\section{Author details}

${ }^{1}$ Department of Nutrition, School of Public Health, Iran University of Medical Sciences, Tehran, Iran. ${ }^{2}$ Department of Clinical Nutrition and Dietetics, Faculty of Nutrition and Food Technology, National Nutrition and Food Technology, Research Institute Shahid Beheshti University of Medical Science, Tehran, Iran. ${ }^{3}$ Endocrinology and Metabolism Research Center, Endocrinology and Metabolism Clinical Sciences Institute, Tehran University of Medical Sciences, Tehran, Iran. ${ }^{4}$ Department of Medical Emergencies, Qom University of Medical Sciences, Qom, Iran. ${ }^{5}$ Non-Communicable Diseases Research Center, Endocrinology and Metabolism Population Sciences Institute, Tehran University of Medical Sciences, Tehran, Iran. ${ }^{6}$ Development of Research and Technology Center, Deputy of Research and Technology, Ministry of Health and Medical Education, Tehran, Iran. ${ }^{7}$ Social Determinants of Health Research Center, Alborz University of Medical Sciences, Karaj, Iran. ${ }^{8}$ Non-Communicable Diseases Research Center, Alborz University of Medical Sciences, Karaj, Iran. ${ }^{9}$ Students Research Committee, Alborz University of Medical Sciences, Karaj, Iran. ${ }^{10}$ Chronic Diseases Research Center, Endocrinology and Metabolism Population Sciences Institute, Tehran University of Medical Sciences, Tehran, Iran.

Received: 5 November 2020 Accepted: 6 April 2021

Published online: 17 April 2021 


\section{References}

1. Curi R, Lagranha CJ, Doi SQ, Sellitti DF, Procopio J, Pithon-Curi TC, et al. Molecular mechanisms of glutamine action. J Cell Physiol. 2005;204:392-401.

2. Grau T, Bonet A, Minambres E, Pineiro L, Irles JA, Robles A, et al. The effect of $\mathrm{L}$-alanyl-L-glutamine dipeptide supplemented total parenteral nutrition on infectious morbidity and insulin sensitivity in critically ill patients. Crit Care Med. 2011;39:1263-8.

3. Dock-Nascimento DB, de Aguilar-Nascimento JE, Magalhaes FMS, Caporossi C, Slhessarenko N, Waitzberg DL. Evaluation of effects of a preoperative 2-hour fast with maltodextrine and glutamine on insulin resistance, acute-phase response, nitrogen-balance, and serum glutathione after laparoscopic cholecystectomy: a controlled randomized trial. J Parenter Enter Nutr. 2012;36:449-55.

4. Gong J, Jing L. Glutamine induces heat shock protein 70 expression via O-GlcNAc modification and subsequent increased expression and transcription activity of Heat shock factor-1. Miner Anestesiol. 2011;77:488-95.

5. Wischmeyer PE, Kahana M, Wolfson R, et al. glutamine induces heat shock protein and protects against endotoxin shock in the rat. J Appl Physiol. 2001;90:2403-10.

6. Brennan L, Corless M, Hewage C, et al. 13C NMR analysis reveals a link between L-glutamine metabolism, D-glucose metabolism and gammaglutamyl cycle activity in a clonal pancreatics cell line. Diabetologia. 2003;46:1512-21.

7. Li C, Buettger C, Kwagh J, Matter A, Daikhin Y, Nissim IB, et al. A signaling role of glutamine in insulin secretion. J Biol Chem. 2004;279(14):1393-401.

8. Heshmati J, Morvaridzadeh M, Sepidarkish M, et al. Effects of Melissa officinalis (Lemon Balm) on cardio-metabolic outcomes: a systematic review and meta-analysis. Phytother Res. 2020:34:3113-23.

9. Boza JJ, Turini M, Moënnoz D, Montigon F, Vuichoud J, Gueissaz N, et al. Effect of glutamine supplementation of the diet on tissue protein synthesis rate of glucocorticoid-treated rats. Nutrition. 2001;17:35-40.

10. Holecek M, Skopec F, Skalska H, Sprongl L. Effect of alanyl-glutamine on leucine and protein metabolism in endotoxemic rats. J Parenter Enteral Nutr. 2000;24:215-22.

11. Opara EC, Petro A, Tevrizian A, Feinglos MN, Surwit RS. L-glutamine supplementation of a high fat diet reduces body weight and attenuates hyperglycemia and hyperinsulinemia in C57 BL/6 J mice. J Nutr. $1996 ; 126: 273$

12. Greenfield JR, Farooqi IS, Keogh JM, Henning E, Habib AM, Blackwood A, et al. Oral glutamine increases circulating glucagon-like peptide 1, glucagon and insulin concentrations in lean, obese, and type 2 diabetic subjects. Am J Clin Nutr. 2009;89:106-13.

13. Jafari-Vayghan $\mathrm{H}$, Varshosaz $\mathrm{P}$, Hajizadeh-Sharafabad F, Razmi HR, Amirpour M, Tavakoli-Rouzbehani OM, Alizadeh M, Maleki V. A comprehensive insight into the effect of glutamine supplementation on metabolic variables in diabetes mellitus: a systematic review. Nutr Metab. 2020;17(1):1-4

14. Houdijk AP, Rijnsburger ER, Jansen J, et al. Randomised trial of glutamineenriched enteral nutrition on infectious morbidity in patients with multiple trauma. Lancet. 1998;352:772-6.

15. Jian ZM, Cao JD, Zhu XG, et al. The impact of alanyl-glutamine on clinical safety, nitrogen balance, intestinal permeability, and clinical outcome in postoperative patients: a randomized, double blind, controlled study of 120 patients. J Parenter Enteral Nutr. 1999;23:S62-6.

16. Hong RW, Rounds JD, Helton WS, Robinson MK, Wilmore DW. Glutamine preserves liver glutathione after lethal hepatic injury. Ann Surg. 1992;215:114-9.

17. van der Hulst RR, van Kreel BK, von Meyenfeldt MF, et al. Glutamine and the preservation of gut integrity. Lancet. 1993;341:1363-5.

18. Higgins JP, Altman DG, Gøtzsche PC, et al. The Cochrane collaboration's tool for assessing risk of bias in randomised trials. BMJ. 2011;343:d5928.

19. Hozo S, Djulbegovic B, Hozo I. Estimating the mean and variance from the median, range, and the size of a sample. BMC Med Res Methodol. 2005;5:13.

20. Whitehead A, Whitehead J. A general parametric approach to the metaanalysis of randomized clinical trials. Stat Med. 1991;10:1665-77.

21. Higgins JP, Thompson SG, Deeks JJ, Altman DG. Measuring inconsistency in meta-analyses. BMJ. 2003;327:57-560.
22. StataCorp. Stata Statistical Software: Release 10; 2007. College Station, TX: StataCorp LP.

23. Singh M, Chaudhary M, Vashistha A, Kaur G. Evaluation of effects of a preoperative 2-hour fast with glutamine and carbohydrate rich drink on insulin resistance in maxillofacial surgery. J Oral Biol Craniofac Res. 2015;5(1):34-9.

24. Laviano A, Molfino A, Lacaria MT, Canelli A, De Leo S, Preziosa I, et al. Glutamine supplementation favors weight loss in nondieting obese female patients. Eur J Clin Nutr. 2014;68(11):1264-6.

25. Letellier G, Mok E, Alberti C, De Luca A, Gottrand F, Cuisset JM, et al. Effect of glutamine on glucose metabolism in children with Duchenne muscular dystrophy. Clin Nutr. 2013;32(3):386-90.

26. Bakalar B, Duska F, Pachl J, Fric M, Otahal M, Pazout J, et al. Parenterally administered dipeptide alanyl-glutamine prevents worsening of insulin sensitivity in multiple-trauma patients. Crit Care Med. 2006;34(2):381-6.

27. Cui Y, Hu L, Liu YJ, Wu YM, Jing L. Intravenous alanyl-L-glutamine balances glucose-insulin homeostasis and facilitates recovery in patients undergoing colonic resection. Eur J Anaesthesiol. 2014;31(4):212-8.

28. Hissa MN, Vasconcelos RC, Guimarães SB, Silva RP, Garcia JH, Vasconcelos $P R$, et al. Preoperative glutamine infusion improves glycemia in heart surgery patients. Acta Cir Bras. 2011;26(Suppl 1):77-81.

29. Mansour A, Mohajeri-Tehrani MR, Qorbani M, Heshmat R, Larijani B, Hosseini S. Effect of glutamine supplementation on cardiovascular risk factors in patients with type 2 diabetes. Nutrition. 2015:31(1):119-26.

30. Lomivorotov WV, Efremov SM, Shmirev VA, Ponomarev DN, Svyatchenko AV, Deryagin MN, Lomivorotov VN, Karaskov AM. Does glutamine promote benefits for patients with diabetes mellitus scheduled for cardiac surgery? Heart Lung Circ. 2013;22(5):360-5.

31. Engel JM, Pitz S, Mühling J, Menges T, Martens F, Kwapisz M, et al. Role of glutamine administration on T-cell derived inflammatory response after cardiopulmonary bypass. Clin Nutr. 2009;28(1):15-20.

32. Cavalcante AA, Campelo MW, de Vasconcelos MP, Ferreira CM, Guimarães $\mathrm{SB}, \mathrm{Garcia} J \mathrm{H}$, et al. Enteral nutrition supplemented with L-glutamine in patients with systemic inflammatory response syndrome due to pulmonary infection. Nutrition. 2012;28(4):397-402.

33. Ockenga J, Borchert K, Rifai K, Manns MP, Bischoff SC. Bischoff. Effect of glutamine-enriched total parenteral nutrition in patients with acute pancreatitis. Clin Nutr. 2002;21(5):409-16.

34. Marik PE, Bellomo R. Stress hyperglycemia: an essential survival response! Crit Care. 2013;17(2):305.

35. Bar-Or D, Rael LT, Madayag RM, Banton KL, Tanner A, Acuna DL, et al. Stress hyperglycemia in critically ill patients: insight into possible molecular pathways. Front Med. 2019;6:54.

36. Mansour A, Hosseini S, Larijani B, Pajouhi M, Mohajeri-Tehrani MR. Nutrients related to GLP1 secretory responses. Nutrition. 2013;29(6):813-20.

37. Abboud KY, Reis SK, Martelli ME, Zordão OP, Tannihão F, de Souza AZZ, et al. Oral glutamine supplementation reduces obesity, pro-inflammatory markers, and improves insulin sensitivity in DIO Wistar rats and reduces waist circumference in overweight and obese humans. Nutrients. 2019;11(3):536

38. Carlessi R, Rowlands J, Ellison G, de Oliveira Alves HH, Newsholme P, Mamotte C. Glutamine deprivation induces metabolic adaptations associated with beta cell dysfunction and exacerbate lipotoxicity. Mol Cell Endocrinol. 2019;491:110433.

39. Samocha-Bonet D, Wong O, Synnott E-L, Piyaratna N, Douglas A, Gribble FM, et al. Glutamine reduces postprandial glycemia and augments the glucagon-like peptide-1 response in type 2 diabetes patients. J Nutr. 2011;141(7):1233-8.

40. Torres-Santiago L, Mauras N, Hossain J, Weltman AL, Darmaun D. Does oral glutamine improve insulin sensitivity in adolescents with type 1 diabetes? Nutrition. 2017;34:1-6.

41. Schwimmer JB, Ee L, Zheng S, Tso P. Glutamine promotes triglyceride absorption in a dose-dependent manner. Am J Physiol Gastrointest Liver Physiol. 2002;282(2):G317-23.

42. Badole SL, Chaudhari SM, Bagul PP, Mahamuni SP, Khose RD, Joshi AC, et al. Effect of concomitant administration of L-glutamine and cycloart23-ene-33, 25-diol (B2) with Sitagliptin in GLP-1 (7-36) amide secretion, biochemical and oxidative stress in streptozotocin-nicotinamide induced diabetic Sprague Dawley rats. PLoS ONE. 2013;8(8):e72817.

43. Chuang I-C, Huang M-S, Huang L-J, Chou S-H, Tsai T-N, Chen Y-C, et al, Prophylactic inhalation of L-alanyl-L-glutamine enhances heat shock 
protein 72 and attenuates endotoxin-induced lung injury in rats. Physio Res. 2015;64(4):505-12.

44. Ziegler TR, Ogden LG, Singleton KD, Luo M, Fernandez-Estivariz C, Griffith DP, et al. Parenteral glutamine increases serum heat shock protein 70 in critically ill patients. Intensive Care Med. 2005;31(8):1079-86.

45. Gould RL, Pazdro R. Impact of supplementary amino acids, micronutrients, and overall diet on glutathione homeostasis. Nutrients. 2019;11(5):1056.

46. Clark A, Imran J, Madni T, Wolf SE. Nutrition and metabolism in burn patients. Burns Trauma. 2017;5(1):11.

47. Meynial-Denis D. Glutamine: biochemistry, physiology, and clinical applications. Boca Raton: CRC Press; 2017.

48. Melis GC, Boelens PG, van der Sijp JR, Popovici T, De Bandt J-P, Cynober $L$, et al. The feeding route (enteral or parenteral) affects the plasma response of the dipetide Ala-GIn and the amino acids glutamine, citrulline and arginine, with the administration of Ala-Gln in preoperative patients. Br J Nutr. 2005;94(1):19-26.

49. Coqueiro AY, Rogero MM, Tirapegui J. Glutamine as an anti-fatigue amino acid in sports nutrition. Nutrients. 2019;11(4):863.
50. Cruzat V, Macedo Rogero M, Noel Keane K, Curi R, Newsholme P. Glutamine: metabolism and immune function, supplementation and clinical translation. Nutrients. 2018;10(11):1564.

51. Wernerman J. Glutamine supplementation. Ann Intensive Care 2011;1(1):25.

52. Wischmeyer PE, Dhaliwal R, McCall M, Ziegler TR, Heyland DK. Parenteral glutamine supplementation in critical illness: a systematic review. Crit Care. 2014;18(2):R76.

53. Stehle P, Kuhn KS. Glutamine: an obligatory parenteral nutrition substrate in critical care therapy. BioMed Res Int. 2015;2015:545467.

\section{Publisher's Note}

Springer Nature remains neutral with regard to jurisdictional claims in published maps and institutional affiliations.
Ready to submit your research? Choose BMC and benefit from:

- fast, convenient online submission

- thorough peer review by experienced researchers in your field

- rapid publication on acceptance

- support for research data, including large and complex data types

- gold Open Access which fosters wider collaboration and increased citations

- maximum visibility for your research: over 100M website views per year

At BMC, research is always in progress.

Learn more biomedcentral.com/submissions 